\title{
Satellite SAR Data-based Sea Ice Classification: An Overview
}

\author{
Natalia Zakhvatkina ${ }^{1,2, *}$, Vladimir Smirnov ${ }^{1}$ and Irina Bychkova ${ }^{1}$ \\ 1 Arctic and Antarctic Research Institute, Saint-Petersburg 199397, Russia; vgs@aari.ru (V.S.); \\ bychkova@aari.ru (I.B.) \\ 2 Nansen International Environmental Remote Sensing Center, Saint-Petersburg 199034, Russia \\ * Correspondence: natalyp@aari.ru
}

Received: 13 March 2019; Accepted: 28 March 2019; Published: 31 March 2019

\begin{abstract}
A review of the main approaches developed for sea ice classification using satellite imagery is presented. Satellite data are the main and very often only information source for sea ice classification and charting in the remote arctic regions. The main techniques used for ice classification and ice charting in several national ice services are considered. Advantages and disadvantages of various SAR data-based methods for ice classification are analyzed. It is shown that an increase of SAR technical abilities contributes to the enhancement of sea ice classification reliability. The possible further development of satellite data-based methods for ice classification is discussed.
\end{abstract}

Keywords: sea ice cover; satellite remote sensing; SAR data processing; sea ice classification

\section{Introduction}

Sea ice cover is an essential component of the Arctic environment and plays an important role in the weather and global climate systems. In addition, sea ice has a significant impact on ice navigation and offshore activities in the polar region. Thus, sea ice classification and ice charting are of interest for making management decisions to ensure safety and efficiency of economic activities without damage for sensitive Arctic environment. Currently, remote sensing data are the main and very often only source of information about sea ice conditions in the Arctic.

One of the primary tasks of sea ice charting is to accurately identify the location of the boundary between ice and open water (the ice edge) [1]. Estimation of ice concentration requires the ability to delineate ice and open water $(\mathrm{OW})$ boundaries with finer spatial resolution. One of the main factors determining the ice navigation difficulties in the Arctic is the ice thickness. Other ice state parameters such as cracks, polynyas, fractures, slightly ridged ice, zones of decreased concentration, ridged features, and floes are very important for ice ship's routing. The procedure of recognition of all these navigation-significant sea ice parameters should be operational and close to the near-real-time regime. At present, sea ice charting by national ice services is based on expert analysis of different data received from all available information sources. This information can be derived from satellite data of various spectral ranges [2].

In the last decades, many studies have been conducted to derive data on sea ice characteristics from high-resolution Synthetic Aperture Radar (SAR) images. SAR can provide measurements regardless of the weather conditions and natural illumination with a high spatial resolution. The national ice services of the United States of America, Canada, Russia, Norway, Denmark and Finland employ high-resolution SAR images as the main data source for monitoring sea ice cover for navigation ships, fishing and various marine operations [1,3-5]. The national ice centers produce ice charts according to international and national standards defined by the World Meteorological Organization (WMO) [6]. More data are becoming available and more quickly accessible to the scientific community, generating 
quickly expanding research results and new research questions. The ultimate objective of this paper is to consider existing techniques and to estimate the further development of the satellite data-based methods for the SAR sea ice classification.

\section{Synthetic Aperture Radar}

The development of SAR observing systems for sea ice monitoring started in 1978 with the launch of the satellite SEASAT (USA). The study of daily SAR images acquired regularly over sea ice in the Beaufort Sea shows the data potential for application to the operational mapping of sea ice type and concentration. The Kosmos-1870 (launched in 1987) and then Almaz-1 (launched in 1991) satellites carrying onboard the SAR instruments earnestly confirmed the applicability of satellite images, considered as an important operational data source for oceanology, geology, cartography, geophysics, etc. applications [7].

The era of intensive development of SAR missions resulted in the successful launch of multiple satellites. SARs of ERS-1,2 (European Remote Sensing satellites, European Space Agency (ESA) in 1991 and 1995) were utilized to monitor the sea ice on the Northern Sea Route, ice mapping and forecasts, and to provide detailed information on sea ice to select the ship routes. However, wide operational use of ERS SAR data was limited by its rather narrow swath width and spatial coverage up to $82^{\circ}$ N. The commercial SAR satellite RADARSAT-1 (RS-1, Canadian Space Agency), launched in 1995, provided access to a variety of SAR modes with different incidence angle, resolution and swath width. The ability to regularly acquire the C-band SAR images with $100 \mathrm{~m}$ resolution with up to $500 \mathrm{~km}$ wide swath has fundamentally changed the way that several national ice monitoring agencies now operate, such as the United States National Ice Center (NIC) and the Canadian Ice Service (CIS) [8].

The launch of ENVISAT (Environmental Satellite, ESA) in 2002 with the multiple polarization ability of Advanced SAR (ASAR) data represented a technological improvement of spaceborne SAR systems allowing investigation of polarimetric scattering signatures of various sea ice types and OW at different incidence angles. These studies of sea ice signatures showed the high potential of multipolarized data for application to the operational mapping of sea ice type and concentration $[9,10]$. The new capacity for ice cover monitoring has been shown by research of polarimetric mode data, which are provided by the next generation of satellites. These SAR instruments can alternately transmit horizontally $(\mathrm{H})$ and vertically $(\mathrm{V})$ polarized waves and receive both polarizations in different combinations providing the dual-polarization or fully polarimetric SAR data. RADARSAT-2 (RS-2) launched in 2007 for the Canadian Space Agency has enhanced the measurement of parameters determined by CIS (e.g., ice-edge location, ice concentration, and stage of development) that are important for operational ice monitoring. The launches of $\mathrm{X}$-band TerraSAR-X and TanDEM-X (Germany, in 2007 and 2010), L-band ALOS-2 (Japan Aerospace Exploration Agency, in 2014), C-band Sentinel-1A/B (European Commission and ESA, in 2014 and 2016) and others have provided a large amount of multi-mode SAR images for sea ice observations.

\section{Interactive Sea Ice Charting: GIS-based Techniques}

CIS designed an image display system that comprises a series of servers and workstations as well as GIS software. The integrated system can geocode, pre-process the image, combine a few images to form of mosaic and draw lines to define homogeneous ice zones in the image. Ice charts are drawn for the Canadian Arctic, using all available satellite information, as well as visual ice observations in situ. The U.S. NIC uses SAR data (as well as other information) to provide routine ice thickness estimation, a daily ice edge and marginal ice zone hemispheric analysis via GIS tools. Detailed hemispheric analysis of sea ice types and concentrations is performed weekly in Sea Ice Grid (SIGRID) format [11]. Ice products provide information on sea ice stage of development according to WMO ice nomenclature. The NIC has an active collaboration with the CIS [12].

Finnish Ice Service (FIS) employs satellite data for mapping ice conditions in the Baltic Sea, using GIS-based software to enable the processing of satellite SAR information. Interpretation of satellite 
images is performed by experienced ice experts using GIS technology to polygonize the sea ice areas of the same attributes. This technique requires many ground truth measurements and continuous monitoring of ice conditions. Operative ice information includes daily ice analysis charts, ice thickness analysis, ice model forecasts, etc. Daily ice charts are based on the ice chart of the preceding day, SAR images, observations from icebreakers and coastal stations, and include concentration, typical, maximum and minimum thickness of level ice and a numeral on a five-point scale for ice ridging. This technology has been developed for the Baltic Sea and is currently being developed for the Kara and Barents Seas. In addition, it will be extended to the other arctic seas [13].

The GIS-based system developed at the Danish Meteorological Institute (DMI) efficiently produces digital ice charts in vector format for the Greenland waters using SAR and other satellite data. The ice service at the Norwegian Meteorological Institute routinely processes a greater volume of satellite remote sensing data and mainly focuses on the operational analysis of ice conditions for producing ice charts containing sea ice concentration and delineated areas of fast ice. The Norwegian Ice Service provides ice charts for the European part of the Arctic every weekday. The charts are produced by a manual interpretation of Sentinel-1 (S1) and RS-2 SAR data [12].

In 1975, a concept and beta version of the Automated Ice Information System for the Arctic (ALISA) was developed at the Arctic and Antarctic Research Institute (AARI, St. Petersburg, Russia) [14]. One of the Automated Working Places (AWPs) of this system, AWP "Ice Expert", has been designed to produce the ice information products. GIS-based software AWP "Ice Expert" operates with various satellite information comprising ice information from ground-based and drifting hydrometeorological stations, vessels and icebreakers. This comprehensive information analysis with the previous analysis (ice chart) as the background state allows producing new information products (annotated satellite images and ice charts) by experienced sea ice experts. The polygons of areas with homogeneous ice attributes are labeled by the ice expert and the resulting image is automatically saved in the WMO SIGRID3 standard vector format [11]. The developed automated technique allows working directly in the ArcView GIS environment and compiles the ice chart immediately as a vector shapefile containing information about the boundaries of ice zones and the ice attributes ("ice eggs") within each zone.

Russian State Research Center for Space Hydrometeorology "Planeta" (Moscow) has conducted radar surveys of the Arctic and Antarctic ice cover since 1983 after the launch of the first oceanographic satellite Kosmos-1500. "Planeta" provides digital charts of ice coverage conditions for the Arctic seas based on satellites data. The "Planeta" technology implies a combination of automated and interactive techniques to process visible, infrared or microwave satellite data. The satellite images are pre-processed in automated mode. In the interactive mode, the ice parameters (age, concentration, ice forms, etc.) are interpreted on satellite images and displayed on the ice chart. In addition, the designed GIS-based software "Planeta Monitoring" employs supervised classifications based on Bayesian maximum likelihood for normal feature vectors distribution, and the K-means clustering algorithm [15].

\section{SAR Data-based Ice Classification}

SARs emit the microwave radiation toward the Earth's surface and receive the reflected echo by the same antenna recording the amplitude and phase. Consequently, a SAR image represents the intensity of radar reflections from the surface, which is measured by the value of the backscattering coefficient $\left(\sigma^{\circ}\right)$. The information derived from SAR image depends on the radar frequency, polarization, and incidence angles, as well as the backscattering intensity of the given ice type, is influenced by the physical and dielectric properties of ice $[5,15,16]$. Ice thickness cannot be directly derived from SAR images but can be only roughly estimated from the ice stage of development (ice types). The automatic interpretation of SAR images is very challenging since SAR image interpretation is complicated by the ambiguity of sea ice backscatter. In addition, the need to quickly and routinely process of many delivered SAR images may require the development of the automated techniques. Therefore, 
the creation of robust automated SAR imagery processing systems has been and remains a very urgent task for researchers.

The most common approach to detect sea ice types is the use of the SAR image characteristic - tone or brightness-determined by the sea ice backscatter. The ability to detect different ice stages of development is very dependent on the geographic region and season $[8,17,18]$. The University of Kansas began to study the use of expert systems in sea ice classification from SAR since 1990 resulting in various techniques to measure and identify sea ice features in SAR imagery. The combination of the dynamic local thresholding and an expert system with human geophysical knowledge were investigated for ice-water segmentation and ice type classification from ERS-1 SAR data. The technique uses multiple thresholdings (selected by the dynamic thresholding method) and correlation to extract intermediate result images, which are then morphologically cleaned and recombined through a structural growing technique, resulting in distinctions among three ice thickness classes: 0-30 cm, 30-200 cm, and $>200 \mathrm{~cm}$. The obtained ice classes and their characteristics, which represent a fullness of features in terms of shape, are fed to the established expert system. The proper labeling for the ice thickness classes in the final result image are achieved using geophysical classification knowledge (ice growth and behavior (geometry), geographical, and historical) to supplement the original classification. The proposed dynamic thresholding technique offers good separation of ice classes. Inherent problems caused by the ambiguity of the SAR images ice intensity under varying environmental conditions, as well as windy OW, are remedied to a large extent by the expert systems analysis $[19,20]$.

In 1992, the Geophysical Processor System (GPS) was developed at the Alaska Satellite Facility (ASF) Synthetic Aperture Radar Data Center, established at the University of Alaska, which was designed to regularly automatic sea ice classification from SAR [21]. The automated classification system was developed for single polarized SAR images from ERS-1 and jointly employed an ISODATA cluster analysis and the Look-Up Tables (LUTs) contain the expected backscatter coefficients of various ice types for a specific geographical region and season [22,23]. The air temperature fields received from the National Meteorological Center are used to select the appropriate LUTs to be used for classifying sea ice types in the SAR imagery. The use in the classification algorithm of only the backscatter values limited the number of distinguished sea ice types to four, and in the summer period to 2-3. The method of LUTs utilization allows distinguishing four ice types in winter: multiyear ice (MYI), rough first-year ice (FYI), smooth FYI, and a class that combines new ice and smooth OW. The most reliable results of GPS ice types classification were obtained for the estimation of sea ice in the central Arctic. The general conclusion was that the performance of the algorithm reveals a considerable dependence on the ice cover characteristics in certain regions but does an excellent job of mapping sea ice in regions to which it is optimally adapted [22,23].

In 1998, Multi-Year Ice Mapping System (MIMS) at the University of Colorado was developed to quickly identify of the high-latitude old ice using uncalibrated SAR images from RADARSAT. A local dynamic thresholding algorithm using the Fisher criterion automatically maps and contours multiyear (old) ice. MIMS was tested and evaluated at the Naval Research Laboratory at the Stennis Space Center (NRLSSC) in Mississippi [24,25]. In addition, in 1998, a beta version of the fully automated system was designed and delivered to NIC and NRLSSC. The Advanced Reasoning using Knowledge for Typing of Sea ice (ARKTOS) system, evolved over more than 10 years, is a SAR-based sea ice classification system incorporated the knowledge-based rules of regional ice features to interpret RADARSAT SAR images [26]. After pre-processing of the input SAR image, ARKTOS applies a watershed region growing segmentation technique to identify intensity homogeneous regions (segments) in the image. A set of 25 attributes, which describe the properties of each segment, such as average intensity, area, shape and other spatial characteristics, and the simple texture-based statistics, is computed. Each segment is then classified according to a set of rules derived from the knowledge and ice experts experience using Dempster-Shafer belief system by looking for satisfied conditions. The algorithm allows distinguishing four classes: OW, new ice, FYI and MYI. The main advantage of ARKTOS is it is 
a feature-based approach, while most knowledge-based systems are pixel-based. Human experts do not analyze the images at the pixel level; instead, they look at regions and features and reason about them. The ARKTOS system can classify SAR sea ice data automatically in an operational regime by simulating logical conclusions used by ice experts in the process of interpretation $[27,28]$.

Similar to the GPS system for the processing of geophysical data products, the RADARSAT Geophysical Processor System (RGPS) was developed at the Jet Propulsion Laboratory and installed in the ASF since 1999. The RGPS generated many products built on each other. The elaborate operational system classifies Scanning Synthetic Aperture Radar (ScanSAR) mode images of the RS-1 SAR in winter into five classes combining the ice backscatter values with ice motion and an empirical relation between accumulated freezing-degree days and ice thickness. The system identifies MYI, FYI rough, FYI smooth, and a class that combines new ice and smooth OW [29,30].

Finnish Meteorological Institute (FMI) has developed several generations of algorithms for the estimation of sea ice concentration, and now offers precise real-time information on ice cover and concentration for the Baltic Sea. The Baltic Sea ice and OW discrimination with $90 \%$ accuracy based on thresholding of segment-wise local autocorrelation using SAR images was presented by Karvonen et al. [31]. Then, Karvonen (2010) [32] showed that several classes of sea ice can be distinguished by selecting the boundaries in the RS-1,2 and ENVISAT SAR images using the Canny edge detection. These methods can well distinguish OW areas, as well as different ice types and areas with certain types of ice characteristics (for example, cracks or ridges). A comparison of the ice-water classification results of these two algorithms application was presented by tests with RS-2 and ENVISAT SAR data that showed the classification accuracy over $89.4 \%$ compared with ice maps of the Baltic Sea manually produced by the FIS. For training data, the classification result of both methods has more than $92 \%$ accuracy [32,33]. A fully automated algorithm using dual-polarized ScanSAR wide mode RS-2 data for sea ice concentration retrieval [34] has been applied by FIS in an operational test mode since 2014. The new iteration of sea ice concentration algorithm based on Neural Networks (NN) utilizing S1 double-polarization data was developed for the Baltic Sea. Backscattering coefficients, several texture features, and spectral gradient and polarization ratios extracted from the Advanced Microwave Scanning Radiometer-2 (AMSR2) data are used as input. The sea ice concentration estimates are computed for each SAR segment after a SAR segmentation, i.e., the NN inputs are segment-wise median values [35]. The fully automated sea ice concentration algorithm produces a daily mosaic covering the Baltic Sea, and it is planned to apply it over the Barents and Kara Seas.

MAp-Guided Sea Ice Classification (MAGIC) system developed at the University of Waterloo [36,37] has been extended for automated ice-water discrimination on RS-2 dual-polarization images based on a combination of an Iterative Region Growing using Semantics (IRGS) classification and a pixel-based Support Vector Machine (SVM) approach. IRGS, developed at the University of Waterloo in the System Design Engineering department, performs the segmentation of the polygons via a watershed algorithm [38]. SVM classifier uses backscatter and SAR texture features to assign ice-water labels after IRGS segmentation. The MAGIC system has been tested on the groundtruthed RS-2 dual polarization SAR scenes of the Beaufort Sea containing a variety of ice types and water across melt, summer, and freeze-up periods. The average classification accuracy was found to be up to $96.47 \%[37,39,40]$. MAGIC has been developed as a modular system of an operational tool to be inserted into CIS operations.

The Norwegian Meteorological Institute developed an automated system for sea ice classification based on cross-polarization SAR data implemented at the Norwegian Ice Service [41]. Pre-processed S1 SAR images are used to automatically reveal OW and sea ice concentration [42]. The Norwegian Ice Service currently provides the automatically generated daily ice charts for the Arctic in experimental test regime. The operational daily ice maps continue to be provided by sea ice experts using RS-2, S1 SAR and other data. 


\section{Discussion}

\subsection{Ice Classification and SAR Technical Abilities}

Due to the large extent of sea ice in polar and sub-Arctic regions as well as the difficulties with in situ observations in those regions, remote sensing is the only practical way to estimate the ice cover conditions at the space and time scales required. The qualitative improvement of the environmental monitoring on a regional and global basis using SAR can be reached with advances in satellite capabilities, as well as in processing algorithm development.

The technical ability to obtain multi-polarization (full- and double-polarization) SAR images improves the classification and segmentation of sea ice compared to single polarization images. Calm water (at low wind speed) has a low reflected signal resulting in a dark tone in SAR image, almost the same as a level FYI. Detection of OW affected by strong wind on a background of sea ice is simplified using SAR images with two polarizations ( $\mathrm{HH}$ and $\mathrm{HV}$ ) due to the significant difference in the backscatter signal from water and ice. The quantitative measurements by Arkett et al. [43] substantiate that co-polarized channels provide valuable information to an ice analyst. The coand cross-polarized ratio is known to provide an excellent measure to distinguish OW and ice types [10,44-46]. Nakamura et al. [44] proposed a polarimetric decomposition technique to classify sea ice of the Okhotsk Sea based on multi-polarization (HH and VV) and dual-frequency (L- and $\mathrm{X}$-band) SAR-data. The VV/HH backscattering ratio provides better sea ice classification capability. The algorithm for retrieving ice thickness based on the backscattering ratio was improved by the empirical Integral-Equation Method (IEM) surface scattering model [47]. The algorithm performs better than previous retrievals, showing good agreement with in situ measurements of thickness data using L-band Pi-SAR (the multipolarized airborne SAR with X-and L-bands) with the root mean square error (MSE) of $7 \mathrm{~cm}$ (compared to C-band ASAR data with MSE of $13.6 \mathrm{~cm}$ ). Nakamura et al. [47] also concluded that L-band SAR was more useful for thickness retrieval than the C-band.

More advanced dual-polarized SAR data show the possibility of a decision tree classifier for sea ice types and OW discrimination using estimated statistical thresholds for winter. Open water is unambiguously discriminated (except thin sea ice) from smooth FYI, rough FYI, and MYI using a co-polarized ratio threshold with $>99 \%$ accuracy [48]. The advantages of using the RS-2 double-polarized SAR image data for automatic unsupervised segmentation of sea ice are discussed in [49].

The assessment of the full polarimetric SAR images $(\mathrm{HH}, \mathrm{HV}, \mathrm{VH}$, and $\mathrm{VV})$ is presented in [50]. The full polarimetric mode of SAR imagery contains complete information about ice cover properties and can improve the sea ice classification accuracy [10,51-53]. An approach to analyzing the fully polarimetric images was introduced by Freeman and Durden [54], who decomposed the received signal of fully polarimetric data into the contributions of independent scattering mechanisms (Freeman-Durden decomposition). Scheuchl et al. [55,56] applied the proposed technique in combination with the Wishart distribution to the multifrequency and multipolarized SIR-C (the shuttle Spaceborne Imaging Radar) data and the airborne SAR imagery. The decomposition method provides a consistent physical description of the scattering processes showing the potential for the identification of ice types using polarimetric SAR data. Applied to dual-frequency data, the method can utilize the different information content of both frequencies and allows thin ice, FYI and MYI to be distinguished. The potential of supervised K-means and maximum likelihood (ML) classifications of various SAR polarimetric data to three pre-identified sea ice types and wind-roughened OW is explored in [57]. The advantages of the full polarimetric data for sea ice mapping is limited by the narrow image swath in the purpose of operational sea ice classification and can be useful to monitor small local areas $[45,58,59]$. The upcoming SAR of Canadian satellites RADARSAT Constellation Mission $(\mathrm{RCM})$ in addition to polarimetric modes will provide data of new polarization configuration -hybrid polarization, also known as compact polarization (CP). Several studies assessing the possibility for discrimination of ice types and OW using SAR data obtained in the CP mode have shown promising 
results [60-62]. The proposed CP SAR data will have a swath width up to $500 \mathrm{~km}$ and could be a good choice for operational sea ice observation using SAR [63].

Moreover, to improve the SAR data classification, more complex datasets can be applied. In addition to using the multichannel, fully polarimetric images data can be supplemented by fusion between data acquired by different SAR sensors or between SAR data and multispectral images [53,64-69]. Another focus, when images acquired by different sensors are combined, is the availability of imagery with different resolutions that of advantage for sea ice classification [70].

Other potential ability to streamline the ice mapping services is to enhance the satellite data processing techniques. Various approaches have been developed to automate the process of sea ice type classification as well as the location of the ice edge and OW in SAR imagery during the past years. Since several winter sea ice stages of development (types or age) and OW can have the same tonal properties, which represent backscatter values $[4,5,23]$, the backscatter at a single pixel is insufficient to distinguish between ice categories. A single-polarization ERS-1 SAR image intensity-based classification with LUTs (algorithm proposed by ASF) have been used to identify MYI, smooth and rough FYI, and new ice/open water in the Beaufort and Chukchi Seas [71]. Additional information is required incorporating the spatial context information (e.g., texture) present in SAR images to analyze objects constructed of similar neighboring pixels. The image analysis method that groups adjacent pixels into significant areas and tracks these areas as objects according to their shape, texture, and spectral information is called an object-oriented classification. This object-based classification allows extracting information about image texture within the group of pixels, which is not available in single pixel-based classifications, making the sea ice parameters delineation more accurate. An important advantage of the object-oriented approach is the independence on the speckle noise of SAR images.

Since the texture is manifested due to variations of the measured intensity occurring in scales much larger than the pixel size, the visually considered SAR image structures (floes, ridges, cracks, rafting ice, leads, etc.) may reveal homogeneous or inhomogeneous areas and can be characterized by different textural parameters [5]. The texture feature extraction is a very substantial stage since it affects the quality of the subsequent classification. Many texture features exist across various scales, and it is very important to measure the texture reasonably and effectively. The most widely used techniques to extract the texture information are statistical methods, e.g. wavelet transform, Markov random field (MRF) and others. The most common statistical method is based on a gray level co-occurrence matrix (GLCM). The texture features extraction via GLCM was presented and explored [72-74], and qualitative evidence of its usefulness for sea ice classification has been found as was one of the key steps for image processing improvement [75]. Holmes et al. [75] examined the use of texture features for sea ice classification and recommended incorporating some additional texture features in future work. The grey level co-occurrence probability texture features applicability for sea ice classes discrimination are widely discussed in [76], where Barber and LeDrew [76] achieved the best discrimination between ice types by simultaneously utilizing three GLCM texture features. The GLCM approach demonstrates better results than those of other texture discrimination methods and is extensively applied in texture description [77]. The investigation of texture statistics calculation parameters was also provided in many researchers (e.g., [78,79]).

\subsection{SAR Data-based Methods for Ice Classification}

Many SAR data-based methods for sea ice classification have been proposed utilizing unsupervised or supervised techniques. Autocorrelation methods [31,33], combinations of wavelet-based [80-82], Gabor wavelet techniques [79], MRF [36,83,84], clustering approaches [22,85] have evolved to produce reliable results (see Table 1). 
Table 1. SAR data-based methods for sea ice classification.

\begin{tabular}{|c|c|c|c|}
\hline $\begin{array}{c}\text { Sea Ice } \\
\text { Algorithm }\end{array}$ & $\begin{array}{l}\text { Input/Image Features } \\
+ \text { Additional Method }\end{array}$ & Results and Comments & Reference \\
\hline \multirow{3}{*}{ 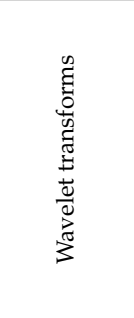 } & ERS-1 & $\begin{array}{c}\text { ice boundary, ice floes; estimated using a visual } \\
\text { interpretation of } 3 \text { scenes }{ }^{1}\end{array}$ & Liu et al. (1997) [80] \\
\hline & RS-1/Entropy (texture) & ice boundary; estimated using visual interpretation ${ }^{1}$ & Gill (2001) [86] \\
\hline & RS-1/texture & $\begin{array}{l}\sim 87 \% \text { for three ice classes (by Discrete Wavelet } \\
\text { Transform); estimated using } 1 \text { scene; results are } \\
\text { consistent with ice observer reports }\end{array}$ & Yu et al., 2002 [81] \\
\hline \multirow{2}{*}{ 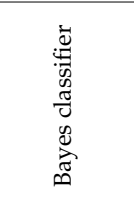 } & ERS/texture & $\begin{array}{l}94.17 \% \text { for seven classes; estimated using } \\
\text { independent test dataset }\end{array}$ & $\begin{array}{l}\text { Soh and Tsatsoulis } \\
\text { (1999) [88] }\end{array}$ \\
\hline & RS-1/texture + MRF & $\begin{array}{l}\text { better detection of smooth and rough FYI, MYI; } \\
\text { estimated using visual interpretation }{ }^{1}\end{array}$ & $\begin{array}{l}\text { Deng and Clausi } \\
2005[84]\end{array}$ \\
\hline \multirow{4}{*}{ 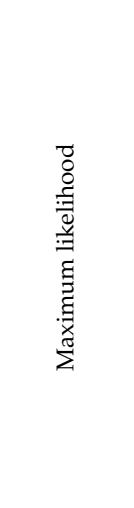 } & RS-1, ENVISAT/texture & $\begin{array}{c}\text { ice/water; estimated with confidence level using } \\
\text { visual interpretation }{ }^{1}\end{array}$ & $\begin{array}{l}\text { Haarpainter and } \\
\text { Solbo } 2007 \text { [90] }\end{array}$ \\
\hline & $\begin{array}{c}\text { RS-2 (quad-pol) } / \text { polarimetric parameters }= \\
\text { couple of best } 3 \text { parameters } \\
\text { combinations selected }\end{array}$ & $\begin{array}{l}90.63 \% \text { for three ice classes and OW; estimated using } \\
\text { independent test dataset of ground truth points }\end{array}$ & $\begin{array}{l}\text { Gill and Yackel (2012) } \\
\text { [57] }\end{array}$ \\
\hline & $\begin{array}{c}\text { ERS-1, RS-1/mean + LUT of expected } \\
\text { backscatter + air temperature } \\
\text { (Bayesian rule) }\end{array}$ & four ice types (winter), and 2-3 classes(summer) & $\begin{array}{c}\text { Kwok } 1992[22] \\
\text { Fetterer et al., } 1994 \\
\text { (see details above) } \\
\text { [23] }\end{array}$ \\
\hline & $\begin{array}{c}\text { RS-2 (quad-pol)/co- and cross-pol ratio } \\
+ \text { kurtosis }\end{array}$ & 7 classes; estimated using 2 training images 1 & Moen et al., 2015 [51] \\
\hline \multirow{6}{*}{ 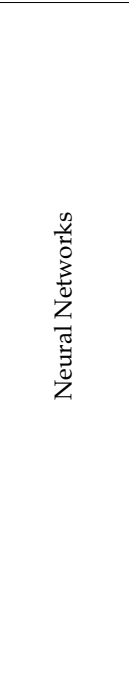 } & $\begin{array}{l}\text { RS-2 }(\mathrm{HH}, \mathrm{HV}) / \text { polarization and gradient } \\
\text { ratios of four AMSR2 radiometer channels }\end{array}$ & $\begin{array}{c}\text { Baltic ice concentration is underestimated with } \\
\text { signed error } 3.9 \% \text { using FMI ice charts independent } \\
\text { test dataset of } 10 \text { scenes }\end{array}$ & $\begin{array}{c}\text { Karvonen, } 2014 \\
\text { (see details above) } \\
\text { [34] }\end{array}$ \\
\hline & $\begin{array}{c}\mathrm{S} 1(\mathrm{HH}, \mathrm{HV}) / \text { mean, texture, polarization } \\
\text { and gradient ratios of four AMSR2 } \\
\text { radiometer channels }\end{array}$ & $\begin{array}{c}\text { Baltic ice concentration is overestimated with signed } \\
\text { error 3.8\% using FMI ice charts independent test } \\
\text { dataset of for } 50 \text { scenes }\end{array}$ & Karvonen 2017 [35] \\
\hline & ENVISAT $(\mathrm{HH}) /$ mean + texture & $\begin{array}{l}80 \% \text { for } 4 \text { classes; estimated using independent } \\
\qquad 20 \text { scenes }\end{array}$ & $\begin{array}{l}\text { Zakhvatkina et al., } \\
\quad 2013 \text { [89] }\end{array}$ \\
\hline & TerraSAR-X (VV)/texture & $\begin{array}{l}\sim 83 \% \text { for three ice classes and OW; estimated using } \\
\text { test datasets from } 3 \text { scenes }\end{array}$ & Ressel et al, 2015 [52] \\
\hline & $\begin{array}{l}\text { TerraSAR-X }(\mathrm{HH}, \mathrm{VV}) / \text { co-pol ratio, } \\
\text { polarimetric features }\end{array}$ & $\begin{array}{l}\sim 95 \% \text { for three ice classes and OW; estimated using } \\
\text { test datasets from } 3 \text { scenes }\end{array}$ & Ressel et al, 2016 [45] \\
\hline & $\begin{array}{c}\text { ALOS-2 and } \mathrm{S} 1(\mathrm{HH}, \mathrm{HV}) / \mathrm{co}-\text { and cross-pol } \\
\text { ratios, incidence angle, } \\
\text { autocorrelation (texture) }\end{array}$ & $\begin{array}{l}\text { S1: } 87.23 \% \text { and } 89.33 \% \text {; ALOS-2: } 84.17 \% \text { and } 85.2 \% \\
\text { for three classes compared with manual ice charts } \\
\text { and the AMSR2 data; estimated using independent } \\
12 \text { S1 and } 13 \text { ALOS-2 scenes respectively }\end{array}$ & $\begin{array}{l}\text { Aldenhoff et al., } 2018 \\
\text { [69] }\end{array}$ \\
\hline \multirow{2}{*}{ 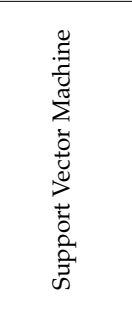 } & RS-2/texture + IRGS segmentation & $\begin{array}{l}96.5 \% \text { for ice edge/open water; estimated over } \\
\text { groundtruthed } 20 \text { scenes }\end{array}$ & Leigh et al., 2014 [39] \\
\hline & RS-2/texture + decision tree & $\begin{array}{l}\text { 91.7\% for four ice classes and OW; estimated using } \\
\text { independent test dataset }\end{array}$ & Liu et al., 2015 [93] \\
\hline
\end{tabular}

${ }^{1}$ Numerical accuracy not provided. The authors mentioned that no general validation is presented because there was one or several scenes and lack of a representative dataset. ${ }^{2}$ CBERS-02B is the China-Brazil Earth Resources Satellite (optical images). ${ }^{3}$ PCA, principal component analysis. ${ }^{4}$ MASIE, Multisensor Analyzed Sea Ice Extend product, provided by NIC. 
Numerous attempts have been made to develop an automatic algorithm for ice/ocean discrimination using SAR data $[28,31,48,90,96]$. Based on the early studies in $[80,86]$, a novel method of automatic detection of the ice edge in dual-polarized RS-2 SAR images was proposed to employ the curvelet transform and active contour method [97]. Comparison of the ice edge with that from manually analyzed SAR images demonstrates the effective detection of the ice edge in SAR images by the proposed method.

A semi-automated sea ice classification algorithm based on fuzzy rules is presented in [96] for RS-1 data over the Arctic Ocean and has been evaluated for retrieval of the calm OW, wind-roughened water, and sea ice in low and high concentrations. This semi-automatic fuzzy-logic algorithm was extended for sea ice classification using derived statistical and texture image features [98]. GLCM entropy measure was found to be effective in classifying SAR images. The described methods were used by the DMI.

Another cluster of algorithms for the goals of automated SAR data processing to retrieve sea ice parameters are supervised learning classifications. The supervised learning method requires a training dataset with known samples for the algorithm tuning, and hence the SAR pre-processing to investigate, identify and assign labels to the predefined classes via ice expertise (for instance) is needed. One of the popular methods is neural networks, which gain over the more traditional statistical approaches the ability to implement only the actual data without any prior knowledge on the statistical distribution of the data and determination of their informational content [99]. Another supervised machine learning algorithm widely applied to both sea ice types and ice/water classification last years is a support vector machine [100]. The methods of supervised learning also include a Bayesian classification that is widely used as a theoretically reliable image classification. The difference from other classification methods is that the Bayesian approach is based on the known of a priory probability of a class object existence [101,102]. The combination of these methods and texture features in addition to various segmentation techniques is also successfully used for sea ice type classification.

Several early studies present the successful application of NN in the development of algorithms for sea ice classification from satellite images (e.g., [103-105]). Karvonen [106] presented the pulse-coupled $\mathrm{NN}$ for ice edge detection, segmentation and ice classification in RADARSAT SAR images of the Baltic Sea. The results show the correct classification of new, level FYI, deformed and fast ice, although thick fast ice was classified in some cases as thin level ice. This approach is widely investigated and extended, has several iterations according to the data and some features, and now modified techniques are designed and applied in the routine process of concentration and thickness ice charts drawing in FIS over Baltic Sea for all seasons [34,35].

Bogdanov et al. [91] compared the NN classification with the other supervised learning algorithm based on the linear discriminant analysis (LDA), presented in [107], for ice classification. A multi-layer feed-forward NN was applied to recognize six sea ice types in RADARSAT and ERS SAR images of the Kara Sea. The results of automated classification (see Table 1) are significantly improved by applying the multisensors approach (up to $91.2 \%$ and $90.1 \%$ for NN and LDA methods, respectively). A NN with texture features based on the GLCM was used for classification of ENVISAT ASAR images [89], where the approach of two consistent application of differently trained NN was proposed to improve sea ice types and OW discriminating using one polarization. The same approach is shown in [93] for the sea ice type classification of RS-2 dual-polarization images using the second SVM in combination with texture features. Liu et al. [93] reasoned that ice concentration should be exploited during the first initial SVM classification and applied as one of the input parameters for a second SVM iteration. They also applied the ML classification to compare its results with the SVM classification. In conclusion, the SVM was found to be more reliable for sea ice classification than ML. SVM is successfully utilized in MAp-Guided Sea Ice Classification system [40] (see Table 1). This system has been under development by MAGIC research group for many years, investigating, applying and improving the combination of various texture extraction, image segmentation and classification approaches [36,37,40,85]. A similar 
approach applying SVM with backscatter and texture features is presented in $[95,108]$ (see Table 1) for classification of S1 data.

The geostatistical approach to automated classification of sea ice from SAR data proposed in [109], where various function values are derived from sub-images in several directions. The classification is then based on feature vectors of parameters (various parameters) calculated from the various functions to summarize spatial sea ice properties. The result yields a segmentation of the study area into homogeneous regions of different sea ice types. It is summarized that a combination of supervised classification (ML) and various parameter mapping yields best results, correctly identifying several sea ice provinces. A province can contain several sea ice types that have experienced the same morphogenetic, kinematic and dynamic processes. Therefore, the geostatistical-statistical classification may be applied to detect processes describing physical characteristics dynamics and deformation states of sea ice.

\section{Conclusions}

Visual interactive interpretation of satellite imagery to derive sea ice information is the main technique for ice charting in several national ice services. The quality of ice classification depends on the skills and experience of ice experts. Experts with experience of airborne visual ice reconnaissance interpret the data of the optical spectral range quite successfully. Visual interpretation of radar data is quite difficult.

Many researchers are skeptical about using only SAR data for ice type classifications or thickness retrieval. The sea ice parameters retrieval from SAR images using the only backscatter is considered unreliable, and the additionally provided other sources (sensors) data to improve the results is welcomed. The possibilities of combining high resolution SAR together with optical data are of great interest due to the wide coverage that SAR offers. However, regular monitoring of the sea ice in the high latitude Arctic in a combination of space-borne SAR and visual spectral range data is limited by the polar night when the sea ice monitoring is highly required. In general, many papers demonstrate that single-frequency sea ice classification results show some class confusion compared with the reference results, indicating radar wavelength dependent limitations for ice type separation. Observations from several SAR frequencies would be of interest to get the most information about sea ice parameters to implement ice classification. Combining of all these researchers" "wishlist" for the accurate routinely mapping of ice in operational regime is restricted by the complexity of near-real-time collocated SAR images acquisition, financial means, computation time and at present is possible only for commercial projects.

Since HV polarization is good to use to distinguish highly smooth surfaces from rough surfaces, utilizing the co-polarization ratios are recommended as well as additional extracted statistical and textural features. New possibilities open up with CP data since they have more polarization information, and give the opportunities to extract new polarimetric features that will improve the ice classification results.

The more consistent SAR image classification result is reached when the processing chain in general comprises the following major steps: (1) image pre-processing (calibration, incidence angular correction, noise correction, filtering, etc.); (2) allocation of ice objects in the case of segmentation usage; (3) image features extraction; and (4) classification. Most methods typically based on a combination of backscatter intensity, second order texture statistics, and some ancillary information applying different numerical models for segmentation and/or classification. A huge number of investigations have been proposed to develop sea ice types or ice edge/open water classifications techniques, but closer to real fully- or semi-automatic systems are based on NN or SVM methods.

Based on this review of the ice cover classification studies using high-resolution SAR images, it seems to be possible to automate main ice types retrieval as well as discriminate ice and OW. The sea ice services use satellite SAR images as the major data source, but the daily operation of sea ice is done 
manually by ice analysts, especially for providing detailed ice charts. This process is very laborious and subjective, so the development of the robust automated ice mapping algorithms is still a hot topic.

Funding: This research was funded by Russian Foundation of Basic Research (grant 18-05-60124).

Conflicts of Interest: The authors declare no conflict of interest.

\section{References}

1. Scheuchl, B.; Flett, D.; Caves, R.; Cumming, I. Potential of RADARSAT-2 data for operational sea ice monitoring. Can. J. Remote Sens. 2004, 30, 448-461. [CrossRef]

2. Smirnov, V.G. Satellite Methods for Determination of Sea Ice Cover Characteristics; AARI: St. Petersburg, Russia, 2011. (In Russian)

3. Jackson, C.R.; Apel, J.R. Synthetic Aperture Radar Marine User's Manual; US Department of Commerce, National Oceanic and Atmospheric Administration, National Environmental Satellite, Data, and Information Serve, Office of Research and Applications: Washington, DC, USA, 2004.

4. Dierking, W. Mapping of different sea ice regimes using images from Sentinel-1 and ALOS synthetic aperture radar. IEEE Trans. Geosci. Remote Sens. 2010, 48, 1045-1058. [CrossRef]

5. Dierking, W. Sea ice monitoring by synthetic aperture radar. Oceanography 2013, 26, 100-111. [CrossRef]

6. World Meteorological Organization. WMO Sea Ice Nomenclature; WHO: Geneva, Switzerland, 1989.

7. Krovotyntsev, V.; Milekhin, O.E. Characteristics of the radar backscattering of the Arctic sea ice using Okean-O1 data. Stud. Earth Space 1998, 2, 68-80. (In Russian)

8. Ramsay, B.; Manore, M.; Weir, L.; Wilson, K.; Bradley, D. Use of RADARSAT Data in the Canadian Ice Service. Can. J. Remote Sens. 1998, 24, 36-42. [CrossRef]

9. Scheuchl, B.; Caves, R.; Flett, D.; De Abr, R.; Arkett, M.; Cumming, I. The potential of cross-polarization information for operational sea ice monitoring. In Proceedings of the Envisat and ERS Symposium, Salzburg, Austria, 6-10 September 2004.

10. Dierking, W.; Skriver, H.; Gudmandsen, P. On the improvement of sea ice classification by means of radar polarimetry. In Proceedings of the 23rd European Association of Remote Sensing Laboratories (EARSeL) Symposium, Ghent, Belgium, 2-5 June 2004; Goossens, R., Ed.; Millpress: Rotterdam, The Netherlands, 2004; pp. 203-209.

11. SIGRID-3: A Vector Archive Format for Sea Ice Georeferenced Information and Data; JCOMM Technical Report Series No. 23; WMO/TD-No.1214; World Meteorological Organization: Geneva, Switzerland, 2014.

12. Sea Ice Information Services in the World; WMO-No.574; World Meteorological Organization: Geneva, Switzerland, 2017.

13. Similä, M.; Lensu, M. Estimating the Speed of Ice-Going Ships by Integrating SAR Imagery and Ship Data from an Automatic Identification System. Remote Sens. 2018, 10, 1132. [CrossRef]

14. Bushuev, A.V.; Volkov, N.A. Remote Measurements of Ice Cover Parameters; Hydrometeoizdat: Leningrad, Russia, 1977. (In Russian)

15. Asmus, V.; Krovotyntsev, V. ; Pyatkin. V. Software Technologies in Satellite Monitoring of the Arctic Ice Cover. J. Sib. Fed. Univ. Eng. Technol. 2015, 6, 680-689. (In Russia) [CrossRef]

16. Ulaby, F.T.; Moore, R.K.; Fung, A.K. Microwave Remote Sensing: Active and Passive; Addison-Wesley: Reading, MA, USA, 1981.

17. Barber, D.G. Microwave remote sensing, sea ice and Arctic climate. Phys. Can. 2005, 61, 105-111.

18. Bushuev, A.V.; Bychenkov, Y.D.; Loschilov, V.S.; Masanov, A.D. Investigation of Ice Cover with Help of Side-Looking Radar (SLR); Hydrometeoizdat: Leningrad, Russia, 1983. (In Russian)

19. Haverkamp, D.; Soh, L.K.; Tsatsoulis, C. A dynamic local thresholding technique for sea ice classification. In Proceedings of the IEEE International Geoscience and Remote Sensing Symposium, Tokyo, Japan, 18-21 August 1993; pp. 638-640.

20. Haverkamp, D.; Soh, LK.; Tsatsoulis, C. A comprehensive, automated approach to determining sea ice thickness from SAR data. IEEE Trans. Geosci. Remote Sens. 1995, 33, 46-57. [CrossRef]

21. Kwok, R.; Baltzer, T. The geophysical processor system at the Alaska SAR Facility. Photogramm. Eng. Remote Sens. 1995, 61, 1445-1453. 
22. Kwok, R.; Holt, B. Identification of Sea Ice Types in Spaceborne Synthetic Aperture Radar Data. J. Geophys. Res. 1992, 97, 2391-2402. [CrossRef]

23. Fetterer, F.M.; Gineris, D.; Kwok, R. Sea ice type maps from Alaska Synthetic Aperture Radar Facility imagery: An assessment. J. Geophys. Res. 1994, 99, 22443-22458. [CrossRef]

24. Bertoia, C.; Manore, M.; Andersen, H.S. Mapping Ice Covered Waters from Space; Agencies and Staff of the US Department of Commerce: Washington, DC, USA, 2001.

25. Fetterer, F.; Ye, J. Multi-year ice concentration from Radarsat. In Proceedings of the IEEE International Geoscience and Remote Sensing Symposium, Singapore, 3-8 August 1997; Volume 1, pp. 402-404.

26. Bertoia, C.; Gineris, D.; Partington, K.; Soh, L.-K.; Tsatsoulis, C. Transition from research to operations: ARKTOS-a knowledge-based sea ice classification system. In Proceedings of the IEEE International Geoscience and Remote Sensing Symposium, Hamburg, Germany, 28 June-2 July 1999; Volume 3, pp. 1573-1575.

27. Soh, L.; Tsatsoulis, C. ARCTOS: A Knowledge Engineering Software Tool for Images. Int. J. Hum. Comput. Stud. 2002, 57, 469-496. [CrossRef]

28. Soh, L.; Tsatsoulis, C.; Gineris, D.; Bertoia, C. ARCTOS: An Intelligent System for SAR Sea Ice Image Classification. IEEE Trans. Geosci. Remote Sens. 2004, 42, 229-248. [CrossRef]

29. Kwok, R. The RADARSAT Geophysical Processor System. In Analysis of SAR Data of the Polar Oceans; Springer: Berlin/Heidelberg, Germany, 1998; pp. 235-257.

30. Kwok, R.; Cunninghan, G. Radarsat Geophysical Processor System; User Handbook. Version 1.0; National Aeronautics and Space Administration: Pasadena, CA, USA, 2000.

31. Karvonen, J.; Simila, M.; Makynen, M. Open water detection from Baltic Sea ice Radarsat-1 SAR imagery. IEEE Geosci. Remote Sens. Lett. 2005, 2, 275-279. [CrossRef]

32. Karvonen, J. C-band sea ice SAR classification based on segmentwise edge features. In Geoscience and Remote Sensing New Achievements; Imperatore, P., Riccio, D., Eds.; In-Tech: Vienna, Austria, 2010; pp. 129-146.

33. Karvonen, J. Operational SAR-based sea ice drift monitoring over the Baltic Sea. Ocean Sci. 2012, 8, 473-483. [CrossRef]

34. Karvonen, J.A. A sea ice concentration estimation algorithm utilizing radiometer and SAR data. Cryosphere 2014, 8, 1639-1650. [CrossRef]

35. Karvonen, J. Baltic Sea ice concentration estimation using SENTINEL-1 SAR and AMSR2 microwave radiometer data. IEEE Trans. Geosci. Remote Sens. 2017, 55, 2871-2883. [CrossRef]

36. Maillard, P.; Clausi, D.A.; Deng, H. Map-guided sea ice segmentation and classification using SAR imagery and a MRF segmentation scheme. IEEE Trans. Geosci. Remote Sens. 2005, 43, 2940-2951. [CrossRef]

37. Clausi, D.A.; Qin, A.K.; Chowdhury, M.S.; Yu, P.; Maillard, P. MAGIC: MAp-Guided Ice Classification System. Can. J. Remote Sens. 2010, 36, S13-S25. [CrossRef]

38. Yu, Q.; Clausi, D.A. IRGS: Image segmentation using edge penalties and region growing. IEEE Trans. Pattern Anal. 2008, 30, 2126-2139.

39. Ochilov, S.; Clausi, D.A. Operational SAR sea-ice image classification. IEEE Trans. Geosci. Remote Sens. 2012, 50, 4397-4408. [CrossRef]

40. Leigh, S.; Wang, Z.; Clausi, D.A. Automated ice-water classification using dual polarization SAR satellite imagery. IEEE Trans. Geosci. Remote Sens. 2014, 52, 5529-5539. [CrossRef]

41. Hughes, N.; Wadhams, P. Dual-Polarisation SAR Sea Ice Type Classification and Iceberg Detection in the western Fram Strait. In Proceedings of the ESA Conference on Earth Observation and Cryospheric Science, Frascati, Italy, 13-16 November 2012.

42. Dinessen, F. Operational multisensor sea ice concentration algorithm utilizing Sentinel-1 and AMSR2 data. Geophysical Research Abstracts, EGU2017-19037. In Proceedings of the 19th EGU General Assembly, EGU2017, Vienna, Austria, 23-28 April 2017; Volume 19.

43. Arkett, M.; Flett, D.; De Abrea, R. Sea Ice Type and Open Water Discrimination for Operational Ice Monitoring with RADARSAT-2. In Proceedings of the IEEE International Geoscience and Remote Sensing Symposium, Denver, CO, USA, 31 July-4 August 2006; pp. 1631-1635.

44. Nakamura, K.; Wakabayashi, H.; Naoki, K.; Nishio, F.; Moriyama, T.; Uratsuka, S. Observation of sea-ice thickness in the Sea of Okhotsk by using dual-frequency and fully polarimetric airborne SAR (Pi-SAR) data. IEEE Trans. Geosci. Remote Sens. 2005, 43, 2460-2469. [CrossRef] 
45. Ressel, R.; Singha, S.; Lehner, S.; Rosel, A.; Spreen, G. Investigation into Different Polarimetric Features for Sea Ice Classification Using X-Band Synthetic Aperture Radar. IEEE J. Sel. Top. Appl. Earth Obs. Remote Sens. 2016, 9, 3131-3143. [CrossRef]

46. Collins, M.J.; Livingstone, C.E.; Raney, R.K. Discrimination of sea ice in the Labrador marginal ice zone from synthetic aperture radar image texture. Int. J. Remote Sens. 1997, 18, 535-571. [CrossRef]

47. Nakamura, K.; Wakabayashi, H.; Uto, S.; Naoki, K.; Nishio, F.; Uratsuka, S. Sea-ice thickness retrieval in the Sea of Okhotsk using dual-polarization SAR data. Ann. Glaciol. 2006, 44, 261-268. [CrossRef]

48. Geldsetzer, T.; Yackel, J. Sea ice type and open water discrimination using dual co-polarized C-band SAR. Can. J. Remote Sens. 2009, 35, 73-84. [CrossRef]

49. Yu, P.; Qin, A.K.; Clausi, D.A. Feature extraction of dual-pol SAR imagery for sea ice image segmentation. Can. J. Remote Sens. 2012, 38, 352-366. [CrossRef]

50. Manore, M.; Flett, D.G.; De Abreu, R.A.; Ramsay, B.R. Multi-polarization SAR data for operational ice monitoring. In Proceedings of the IEEE Geoscience and Remote Sensing Symposium, Sydney, Australia, 9-13 July 2001; Volume 3, pp. 1246-1248.

51. Moen, M.-A.N.; Anfinsen, S.N.; Doulgeris, A.P.; Renner, A.H.H.; Gerland, S. Assessing polarimetric SAR sea-ice classifications using consecutive day images. Ann. Glaciol. 2015, 56, 285-294. [CrossRef]

52. Ressel, R.; Frost, A.; Lehner, S. A Neural Network-Based Classification for Sea Ice Types on X-Band SAR Images. IEEE J. Sel. Top. Appl. Earth Obs. Remote Sens. 2015, 8, 3672-3680. [CrossRef]

53. Johansson, A.M.; Brekke, C.; Spreen, G.; King, J.A. X-, C-, and L-band SAR signatures of newly formed sea ice in Arctic leads during winter and spring. Remote Sens. Environ. 2018, 204, 162-180. [CrossRef]

54. Freeman, T.; Durden, S.L. A three-component scattering model for polarimetric SAR data. IEEE Trans. Geosci. Remote Sens. 1998, 36, 963-973. [CrossRef]

55. Scheuchl, B.; Caves, R.; Cumming, I.; Staples, G. Automated Sea Ice Classification Using Spaceborne Polarimetric SAR Data. In Proceedings of the IEEE International Geoscience and Remote Sensing Symposium, Scanning the Present and Resolving the Future, Sydney, Australia, 9-13 July 2001; IEEE Cat. No.01CH37217.

56. Scheuchl, B.; Cumming, I.G.; Hajnsek, I. Classification of fully polarimetric single- and dual-frequency SAR data of sea ice using the Wishart statistics. Can. J. Remote Sens. 2005, 31, 61-72. [CrossRef]

57. Gill, J.P.S.; Yackel, J.J. Evaluation of C-band SAR polarimetric parameters for discriminating of first-year sea ice types. Can. J. Remote Sens. 2012, 38, 306-323. [CrossRef]

58. Moen, M.-A.N.; Doulgeris, A.P.; Anfinsen, S.N.; Renner, A.H.H.; Hughes, N.; Gerland, S.; Eltoft, T. Comparison of feature based segmentation of full polarimetric SAR satellite sea ice images with manually drawn ice charts. Cryosphere 2013, 7, 1693-1705. [CrossRef]

59. Dabboor, M.; Shokr, M. A new Bayesian likelihood ratio test for supervised classification of fully polarimetric SAR data: An application for sea ice type mapping. ISPRS J. Photogramm. Remote Sens. 2013, 84, 1-11. [CrossRef]

60. Dabboor, M.; Geldsetzer, T. Towards sea ice classification using simulated RADARSAT constellation mission compact polarimetric SAR imagery. Remote Sens. Environ. 2014, 140, 189-195. [CrossRef]

61. Singha, S.; Ressel, R. Arctic sea ice characterization using RISAT-1 compact-pol SAR imagery and feature evaluation: A case study over Northeast Greenland. IEEE J. Sel. Top. Appl. Earth Obs. Remote Sens. 2017, 10, 3504-3514. [CrossRef]

62. Dabboor, M.; Montpetit, B.; Howell, S. Assessment of the High Resolution SAR Mode of the RADARSAT Constellation Mission for First Year Ice and Multiyear Ice Characterization. Remote Sens. 2018, 10, 594. [CrossRef]

63. Arkett, M.; Carrieres, T.; Zagon, T.; Zabeline, V.; Buehner, M.; Caya, A.; Pogson, L.; Luo, Y. Preparations by the Canadian Ice Service for Future Earth Observation Missions. In Proceedings of the Earth Observation and Cryosphere Science Conference, Frascati, Italy, 13-16 November 2012. ESA SP-712.

64. Hara, Y.; Atkins, R.G.; Shin, R.T.; Kong, J.A.; Yueh, S.H.; Kwok, R. Application of Neural Networks for Sea Ice Classification in Polarimetric SAR Images. IEEE Trans. Geosci. Remote Sens. 1995, 33, 740-748. [CrossRef]

65. Dierking, W.; Busche, T. Sea Ice Monitoring by L-Band SAR: An Assessment Based on Literature and Comparisons of JERS-1 and ERS-1 Imagery. IEEE Trans. Geosci. Remote Sens. 2006, 44, 957-970. [CrossRef]

66. Bogdanov, A. Neuroinspired architecture for robust classifier fusion of multisensor imagery. IEEE Trans. Geosci. Remote Sens. 2008, 46, 1467-1487. [CrossRef] 
67. Gupta, M.; Scharien, R.K.; Barber, D.G. C-band polarimetric coherences and ratios for discriminating sea ice roughness. Int. J. Oceanogr. 2013, 2013, 567182. [CrossRef]

68. Casey, J.A.; Howell, S.E.; Tivy, A.; Haas, C. Separability of sea ice types from wide swath C- and L-band synthetic aperture radar imagery acquired during the melt season. Remote Sens. Environ. 2016, 174, 314-328. [CrossRef]

69. Aldenhoff, W.; Heuzé, C.; Eriksson, L.E.B. Comparison of ice/water classification in Fram Strait from C-and L-band SAR imagery. Ann. Glaciol. 2018, 59, 112-123. [CrossRef]

70. Dierking, W. Sea ice classification on different spatial scales for operational and scientific use. In Proceedings of the ESA Living Planet Symposium, Edinburgh, UK, 9-13 September 2013.

71. Wohl, G.M. Operational sea ice classification from synthetic aperture radar imagery. Photogramm. Eng. Remote Sens. 1995, 61, 1455-1462.

72. Haralick, R.; Shanmagan, K.; Dinstein, I. Textural features for image classification. IEEE Trans. Syst. Man Cybern. 1973, 3, 610-621. [CrossRef]

73. Shokr, M. Evaluation of second-order texture parameters for sea-ice classification from radar images. J. Geophys. Res. 1991, 96, 10625-10640. [CrossRef]

74. Shuchman, R.A.; Wackerman, C.; Maffett, A.L.; Onstott, R.G.; Sutherland, L.L. The Discrimination of Sea Ice Types using SAR Backscatter Statistics. In Proceedings of the 12th Canadian Symposium on Remote Sensing Geoscience and Remote Sensing Symposium, Vancouver, BC, Canada, 10-14 July 1989; pp. 381-385.

75. Holmes, Q.A.; Nuesch, D.R.; Shuchman, R.A. Textural analysis and real-time classification of sea ice types using digital SAR data. IEEE Trans. Geosci. Remote Sens. 1984, 22, 113-120. [CrossRef]

76. Barber, D.G.; LeDrew, E.F. SAR sea ice discrimination using texture statistics, A multivariate approach. Phtogram. Eng. Remote Sens. 1991, 57, 385-395.

77. Barber, D.G.; Shokr, M.; Soulis, E.; Fernandes, R.; Flett, D.; LeDrew, E.F. A comparison of second order texture classifiers for SAR sea ice. Photogramm. Eng. Remote Sens. 1993, 59, 1397-1408.

78. Baraldi, A.; Parmigiani, F. An investigation of the textural characteristics associated with gray level cooccurrence matrix statistical parameters. IEEE Trans. Geosci. Remote Sens. 1995, 33, 293-304. [CrossRef]

79. Clausi, D.A. An analysis of co-occurrence texture statistics as a function of grey level quantization. Can. J. Remote Sens. 2002, 28, 45-62. [CrossRef]

80. Liu, A.K.; Martin, S.; Kwok, R. Tracking of ice edges and ice floes by wavelet analysis of SAR images. J. Atmos. Ocean. Tech. 1997, 14, 1187-1198. [CrossRef]

81. Yu, Q.; Moloney, C.; Williams, F.M. SAR sea-ice texture classification using discrete wavelet transform based methods. In Proceedings of the IEEE Geoscience and Remote Sensing Symposium, Toronto, ON, Canada, 24-28 July 2002; Volume 5, pp. 3041-3043.

82. Simila, M.; Helminen, J. The identification of the deformed sea ice fields from ERS-1 SAR image by wavelets. In Proceedings of the IEEE Geoscience and Remote Sensing Symposium, Firenze, Italy, 10-14 July 1995; Volume 2, pp. 868-870.

83. Clausi, D.A.; Yue, B. Comparing Cooccurrence Probabilities and Markov Random Fields for Texture Analysis of SAR Sea Ice Imagery. IEEE Trans. Geosci. Remote Sens. 2004, 42, 215-228. [CrossRef]

84. Deng, H.; Clausi, D.A. Unsupervised segmentation of synthetic aperture Radar sea ice imagery using a novel Markov random field model. IEEE Trans. Geosci. Remote Sens. 2005, 43, 528-538. [CrossRef]

85. Similä, M.; Dinessen, F.; Hughes, N.E.; Mäkynen, M. Ice edge detection with dual-polarized SAR data. In Proceedings of the 22nd International Conference on Port and Ocean Engineering under Arctic Conditions, Espoo, Finland, 9-13 June 2013.

86. Gill, R.S. Operational detection of sea ice edges and icebergs using SAR. Can. J. Remote Sens. 2001, 27, 411-432. [CrossRef]

87. Liu, M.; Dai, Y.; Zhang, J.; Zhang, X.; Meng, J.; Xie, Q. PCA-based sea-ice image fusion of optical data by HIS transform and SAR data by wavelet transform. Acta Oceanol. Sin. 2015, 34, 59-67. [CrossRef]

88. Soh, L.K.; Tsatsoulis, C. Texture analysis of SAR imagery using grey level co-occurrence matrices. IEEE Trans. Geosci. Remote Sens. 1999, 37, 780-795. [CrossRef]

89. Zakhvatkina, N.; Alexandrov, V.; Johannessen, O.M.; Sandven, S.; Frolov, I. Classification of sea ice types in ENVISAT synthetic aperture radar images. IEEE Trans. Geosci. Remote Sens. 2013, 51, 2587-2600. [CrossRef]

90. Haarpainter, J.; Solbo, S. Automatic Ice-Ocean Discrimination in SAR Imagery; Norut IT-Rapport; NORUT Northern Research Institute: Tromsø, Norway, 2007. 
91. Bogdanov, A.V.; Sandven, S.; Johannessen, O.M.; Alexandrov, V.Y.; Bobylev, L.P. Multisensor approach to automated classification of sea ice image data. IEEE Trans. Geosci. Remote Sens. 2005, 43, 1648-1664. [CrossRef]

92. Kaleschke, L.; Kern, S. ERS-2 SAR image analysis for sea ice classification in the marginal ice zone. In Proceedings of the 22nd International Geoscience and Remote Sensing Symposium, Toronto, ON, Canada, 24-28 June 2002; Institute of Electrical and Electronics Engineers: Piscataway, NJ, USA; pp. 3038-3040.

93. Liu, H.; Guo, H.; Zhang, L. SVM-based sea ice classification using textural features and concentration from RADARSAT-2 dual-pol ScanSAR data. IEEE J. Sel. Top. Appl. Earth Obs. Remote Sens. 2015, 8, 1601-1613. [CrossRef]

94. Zakhvatkina, N.; Korosov, A.; Muckenhuber, S.; Sandven, S.; Babiker, M. Operational algorithm for ice-water classification on dual-polarized RADARSAT-2 images. Cryosphere 2017, 11, 33-46. [CrossRef]

95. Hong, D.; Yang, C.S. Automatic discrimination approach of sea ice in the Arctic Ocean using Sentinel-1 Extra Wide Swath dual-polarized SAR data. Int. J. Remote Sens. 2018, 39, 4469-4483. [CrossRef]

96. Gill, R.S. SAR Ice Classification Using Fuzzy Screening Method; Scientific Report 02-12; Scientific Report 02-12; Danish Meteorological Institute: Copenhagen, Danmark, 2002.

97. Liu, J.; Scott, K.A.; Gawish, A.; Fieguth, P. Automatic Detection of the Ice Edge in SAR Imagery Using Curvelet Transform and Active Contour. Remote Sens. 2016, 8, 480. [CrossRef]

98. Gill, R.S.; Tonboe, R.T. Classification of GreenIce SAR data using fuzzy screening method. In Arctic Sea Ice Thickness: Past, Present and Future; Wadhams, P., Amanatidis, G., Eds.; Climate Change and Natural Hazards Series 10, EUR22416; European Commission: Brussels, Belgium, 2006.

99. Benediktsson, J.A.; Ersoy, O.K. Neural Network Approaches Versus Statistical Methods in Classification of Multisource Remote Sensing Data win. IEEE Trans. Geosci. Remote Sens. 1990, 28, 540-552. [CrossRef]

100. Cortes, C.; Vapnik, V. Support-Vector Networks. Mach. Learn. 1995, 20, 273-297. [CrossRef]

101. Verspeek, J.A. Sea Ice Classification Using Bayesian Statistics; Royal Netherlands Meteorological Institute (KNMI): De Bilt, The Netherlands, 2006; 30p.

102. OSI SAF Sea Ice Product Manual, v. 3.11 ed.; Eumetsat: Copenhagen, Danmark, 2014.

103. Heerman, P.D.; Khazenie, N. Classification of Multispectral Remote Sensing Data Using a Back-Propagation Neural Network. IEEE Trans. Geosci. Remote Sens. 1992, 30, 81-88. [CrossRef]

104. Atkinson, P.M.; Tatnall, A.R.L. Neural network in remote sensing. Int. J. Remote Sens. 1997, 18, 669-709. [CrossRef]

105. Mejia, C.; Thiria, S.; Tran, N.; Crépon, M.; Badran, F. Determination of the Geophysical Model Function of the ERS-1 Scatterometer by the Use of Neural Networks. J. Geophys. Res. 1998, 103, 12853-12868. [CrossRef]

106. Karvonen, J.A. Baltic Sea ice SAR segmentation and classification using modified pulse-coupled neural networks. IEEE Trans. Geosci. Remote Sens. 2004, 42, 1566-1574. [CrossRef]

107. Wackerman, C.C.; Miller, D.L. An Automated Algorithm for Sea Ice Classification in the Marginal Ice Zone Using ERS-1 Synthetic Aperture Radar Imagery; ERIM: Ann Arbor, MI, USA, 1996.

108. Korosov, A.; Park, J.-W. Very high resolution classification of Sentinel-1A data using segmentation and texture features. In Proceedings of the European Space Agency Living Planet Symposium, Prague, Czech Republic, 9-13 May 2016; Volume 740.

109. Herzfeld, U.C.; Williams, S.; Heinrichs, J.; Maslanik, J.; Sucht, S. Geostatistical and Statistical Classification of Sea-Ice Properties and Provinces from SAR Data. Remote Sens. 2016, 8, 616. [CrossRef]

(c) 2019 by the authors. Licensee MDPI, Basel, Switzerland. This article is an open access article distributed under the terms and conditions of the Creative Commons Attribution (CC BY) license (http://creativecommons.org/licenses/by/4.0/). 